\title{
ESQUISTOSSOMOSE MANSÔNICA EM CAMUNDONGOS EXPERIMENTALMENTE SUBNUTRIDOS*
}

\author{
Luiz Augusto Magalhães** \\ Ana Maria A. Guaraldo** \\ Eliana M. Zanotti-Magalhães ** \\ José F. de Carvalho *** \\ Valdomiro C. Sgarbieri **** \\ Francisco G. de Alcântara ${ }^{* * * *}$
}

\begin{abstract}
MAGALHĀES, L.A. et al. Esquistossomose mansônica em camundongos experimentalmente subnutridos. Rev.Saúde públ., S.Paulo, $20: 362-8,1986$.

RESUMO: Realizou-se estudo sobre o desenvolvimento da esquistossomose mansônica em camundongos submetidos à dieta hipoprotéica. Foram constituídos 4 grupos de Mus musculus "Swiss" da seguinte forma: 1) nāo infectados, normoprotéicos; 2) infectados, normoprotéicos; 3) não infectados, hipoprotéicos e 4) infectados, hipoprotéicos. Os animais foram sacrificados com 60 dias de infecção, aos 90 dias de idade. Verificou-se que os esquistossomos sofreram os efeitos da subnutrição do hospedeiro, principalmente os vermes machos, que além de terem seu desenvolvimento prejudicado, tiveram seu número reduzido aproximadamente pela metade. O número de granulomas foi menor nos roedores subnutridos e o tamanho da lesão foi reduzido. Houve acentuada leucopenia nos animais submetidos à dieta hipoprotéica, principalmente nos infectados subnutridos. A linfopenia e a eosinopenia acentuadas sugeriram que o sistema imunológico do hospedeiro foi afetado pela subnutrição. A taxa de mortalidade foi muito mais elevada nos animais infectados submetidos à dieta hipoprotéica. Concluju-se que os camundongos subnutridos resistiram menos à infecção esquistossomótica apesar de terem apresentado menor número de lesōes granulomatosas.
\end{abstract}

UNITERMOS: Esquistossomose mansônica, complicaçōes. Deficiência de proteína. Camundongo, parasitologia. Camundongo, infecção experimental. Schistosoma mansoni.

\section{INTRODUÇÃO}

Coutinhọ e col.6, em 1972, estudaram clinicamente a evolução da esquistossomose no Nordeste, correlacionando-a com os aspectos nutricionais e concluindo que os resultados obtidos "reforçam, mais uma vez, o papel da desnutrição na evolução da esquistossomose". Recomendam também "a continuação desses estudos para que maiores detalhes possam ser explorados, permitindo conclusōes definitivas a respeito dessa helmintose". Ainda Coutinho5, em 1980, ao estudar o efeito da subnutrição na esquistossomose, escreveu: "Em conclusão, pode-se dizer que a patologia da desnutrição nas parasitoses abrange aspectos variados e alguns deles ainda controvertidos ou apenas superficialmente conhecidos. Por esse motivo, constitui-se importante campo de investigação, ainda relativamente mal explorado dentro de nossa patologia tropical".

Madi e col.12 (1975), tentando reproduzir as alteraçđes detectadas na desnutrição infantil, submeteram ratos albinos jovens a uma dieta pobre em proteinas por periodo de $4 \mathfrak{i}$ a 88 dias. Verificaram transformações patológicas a nivel de tegumento, fígado, pâncreas, intestinos, timo, baço e gânglios linfáticos, expressando comportamento intermediário entre marasmo e kwashiorkor. Esses autores observaram também a inversão da relação albumina- globulina no grupo de ratos subnutridos, com a ocorrência de um acréscimo no teor de globulinas alfa-1 e alfa-2, sem variaçð̃es significantes das frações beta e gama-globulinas.

A inibição da resposta granulomatosa foi observada por Knouft e col.10 (1969), Akpom e col.2,3 (1975) e Akpom 1 (1981) em camundongos esquistossomóticos mantidos com dietas pobres em proteínas e vitaminas.

Coutinho-Abath e col.7 (1962) verificaram, em camundongos infectados por Schistosoma mansoni e submetidos a dietas hiperprotéica, normoprotéica e hipoprotéica, que "o nível de proteína alimentar influi sobre o grau de reatividade do SRE, sendo os

\footnotetext{
* Pesquisa realizada com auxílio financeiro da Fundação de Amparo à Pesquisa do Estado de São Paulo (FAPESP). Proc. 04.Biológico/78/082.

* . Do Departamento de Parasitologia do Instituto de Biologia da Universidade Estadual de Campinas (UNICAMP) - Caixa Postal 6109 - 13081 - Campinas, SP - Brasil.

** Do Instituto de Matemática, Estatística e Ciências da Computação da UNICAMP.

**** Da Faculdade de Engenharia de Alimentos e Agrícola da UNICAMP.

**** Do Departamento de Histologia do Instituto de Biologia da UNICAMP.
} 
fenômenos inflamatórios exsudativos particularmente evidentes no grupo de animais submetidos a regime hiperprotéico".

Não só as defesas do hospedeiro são afetadas pelo estado nutricional; os parasitos também podem sofrer as consequiências dessa condição. De Witt 8,9 (1975) verificou em camundongos esquistossomóticos submetidos a dieta de levedura pobre de "fator

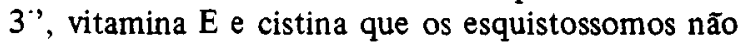
se desenvolviam completamente e muitos não alcançaram a maturidade sexual, apresentando compro. metimento significante da função ovopositora. Entretanto, o referido autor observou, nesses camundongos subnutridos, um número $69 \%$ maior de esquistossomos do que em animais infectados que receberam dieta considerada normal. O mesmo autor observou ainda que, além da dieta deficiente ter diminuido a resistência dos animais ao parasitismo, houve também degeneração necrótica do coração, fígado, músculos e rins.

Nosso objetivo foi avaliar alguns efeitos, no hospedeiro e no parasito, da infeç̧ão esquistossomótica em camundongos submetidos a dieta hipoprotéica.

\section{MATERIAL E MÉTODOS}

Utilizando para a infecção dos roedores, Schistosoma mansoni da linhagem $\mathrm{BH}$, obtidos de Biom. phalaria glabrata procedentes de população de Belo Horizonte, nascidas e infectadas em laboratório, camundongos "Swiss", foram infectados pela cauda com uma suspensão contendo 100 cercárias por roedor (Magalhães 13, 1969).

Foram constituídos quatro grupos de camundongos, seguindo um esquema fatorial com dois fatores (ver, por exemplo, Snedecor e Cochran 14, 1980): infecção e nutrição, cada um com dois niveis. Os quatro grupos são:

I. não infectados, dieta normoprotéica "ad libitum" (controle);

II. infectados, dieta normoprotéica "ad libitum";

III. não infectados, dieta hipoprotéica "ad libitum" e

IV. infectados, dieta hipoprotéica "ad libitum".

Os animais foram alocados aos tratamentos de acordo com disponibilidade de material, de modo que a aleatorização foi prejudicada.

Os tratamentos dietéticos foram iniciados 20 dias após o nascimento dos roedores, por ocasião do desmame. A infecção foi realizada em camundongos fềmeos com 30 dias de idade. Decorridos 60 dias da data de infecção (90 dias de idade), os animais foram novamente pesados e imediatamente sacrificados por deslocamento cervical sendo, então, seu sistema porta-mesentérico perfundido (Yolles e col.15, 1947).
Os esquistossomos, recolhidos por ocasião da necrópsia dos roedores, foram fixados em Raillet -Henry, posteriormente corados pelo carmim-clorídrico e montados em lâmina.

0 fígado e o baço dos camundongos eram retirados para pesagem.

Foram contados os esquistossomos machos e fềmeos, estudada sua morfologia, anotando o número de testículos e ovos do útero. O comprimento desses vermes foi verificado no Visopan da Reichert, sendo a medida tomada com auxílio de curvímetro.

Por ocasião do sacrifício dos roedores, as fezes foram coletadas do reto para a determinação do número de ovos de $S$. mansoni (Komyia e Kobayashi11, 1966).

Após a pesagem e retirada de pequenos fragmentos para corte histológico, o figado dos roedores foi homogeneizado em liquidificador doméstico e determinado o número de granulomas (Brener e col.4, 1956).

Fragmentos do fígado, baço e pulmões de todos os animais utilizados no experimento foram fixados em Bouin para a realização de cortes histológicos de $7 \mu$ de espessura e corados com hematoxilina-eosina.

Para realização do leucograma, esfregaços de sangue colhido do plexo braquial por ocasião da necrópsia foram fixados em álcool metílico e corados pelo May-Grünwald-Giemsa.

$\mathrm{Na}$ Tabela 1 estão especificadas as quantidades de nutrientes constantes das dietas normoprotéica e hipoprotéica em $10 \mathrm{~kg}$ de ração. A composição percentual da mistura salina utilizada consta da Tabela 2. A composição da mistura vitamínica consta da Tabela 3.

Método estatístico: cada animal observado deu um conjunto de respostas (variáveis), de modo que empregamos, para começar, um modelo linear multivariado, para estudar os efeitos dos fatores e de sua interação.

A variável peso foi introduzida como co-variável, que se revelou importante no estudo de várias respostas. De uma maneira descritiva, empregamos também resultados obtidos por modelos univariados para algumas variáveis. Os modelos foram validados por extensa análise de resíduos, para garantir as premissas básicas dos ajustes. Comparações de médias foram feitas pelo método de Ryan-Eniot-Gabriel -Welsch. Em alguns casos, observaçס̄es aberrantes foram eliminadas; para certas respostas, a variável foi transformada. Os cálculos foram feitos em um computador IBM 4341, com o "Statistical Analysis System" (SAS). 
MAGALHÃES, L.A. et al. Esquistossomose mansônica em camundongos experimentalmente subnutridos. Rev. Saúde públ., S. Paulo, $20: 362-8,1986$.

\section{TABELA 1}

Quantidade de nutrientes constantes das dietas normoprotéicas e hipoprotéicas em $10 \mathrm{~kg}$ de ração.

\begin{tabular}{lcc}
\hline Nutrientes & $\begin{array}{c}\text { Dieta normoprotéica (kg) } \\
(20 \% \text { de proteina) }\end{array}$ & $\begin{array}{c}\text { Dieta hipoprotéica }(\mathrm{kg}) \\
\text { (de 4\% a 5,6\% de proteina) (*) }\end{array}$ \\
\hline Caseina & 3,15 & 0,70 \\
Oleo & 0,80 & 0,80 \\
Mistura salina (Tabela 2) & 0,50 & 0,50 \\
Mistura vitamínica (Tabela 3) & 0,20 & 0,20 \\
Sacarose & 1,50 & 1,50 \\
Amido & 3,85 & 6,30 \\
\hline
\end{tabular}

(*) Variação devida ao conteúdo protéico das amostras de caseína utilizadas no experimento.

TABELA 2

Composição percentual de mistura salina

\begin{tabular}{lr}
\hline Componentes & Quantidade (\%) \\
\hline Cloreto de sódio & 25,0600 \\
Molibdato de amônio & 0,0030 \\
Carbonato de cálcio & 29,2900 \\
Sulfato cúprico & 0,1560 \\
Fosfato dibásico de cálcio & 0,4300 \\
Citrato férrico & 0,6200 \\
Sulfato de magnésio & 9,9800 \\
Sulfato de manganês & 0,1210 \\
Iodeto de potássio & 0,0005 \\
Fosfato dibásico de potássio & 34,3100 \\
Selenito de sódio & 0,0020 \\
Cloreto de zinco & 0,0200 \\
\hline
\end{tabular}

TABELA 3

Composição da mistura vitamínica

\begin{tabular}{lc}
\hline Componentes & Quantidades (mg) (*) \\
\hline Vitamina A & $90.000 \mathrm{UI}$ \\
Vitamina D & $10.000 \mathrm{UI}$ \\
Biotina & 2,0 \\
Vitamina E & 500,0 \\
Vitamina K & 150,0 \\
Vitamina B12 & 0,1 \\
Inositol & 200,0 \\
Niacina & 200,0 \\
Riboflavina & 50,0 \\
Cloridrato de tiamina & 50,0 \\
Acido fólico & 7,0 \\
Pantotenato de cálcio & 200,0 \\
Ácido p. aminobenzóico & 200,0 \\
Cloridrato de colina & $7.500,0$ \\
Ácido ascórbico & $4.500,0$ \\
Sacarose e farinha de mandioca torrada & \\
(50\% + 50\%), veiculada para 100 g & $84.390,0$ \\
\hline ( $)$ Exceto para as vitaminas A e D que estão em uni- \\
dades internacionais (UI) & \\
&
\end{tabular}

\section{RESULTADOS}

Os resultados (Tabelas 4 a 9) mostraram que a infecção esquistossomótica provocou aumento altamente significativo do peso do fígado e do baço nos animais tratados com dieta normoprotéica, o mesmo não ocorrendo nos animais infectados submetidos à dieta hipoprotéica. $O$ peso dessas duas vísceras foi significativamente menor nos animais hipoprotéicos, tanto infectados como nos livres de infecção esquistossomótica.

\section{TABELA 4}

Peso corporal médio dos camundongos por grupo e por idade

\begin{tabular}{llcccc}
\hline \multirow{2}{*}{ Infecçāo } & Dieta & $\begin{array}{c}\text { Número } \\
\text { de } \\
\text { animais }\end{array}$ & $30\left(^{*}\right)$ & 60 & $90\left(^{* *}\right)$ \\
\hline não & normo & 33 & 17,55 & 26,31 & 30,19 \\
sim & normo & 27 & 16,93 & 23,67 & 25,12 \\
não & hipo & 30 & 9,70 & 11,86 & 13,19 \\
sim & hipo & 35 & 11,61 & 14,30 & 15,68 \\
\hline
\end{tabular}

(*) data de infecção

$\left({ }^{*}\right)$ data da necropsia

(peso em gramas)

\section{TABELA 5}

Peso médio ajustado das vísceras dos camundongos na ocasião da necropsia.

\begin{tabular}{llccc}
\hline Infecção & Dieta & $\begin{array}{c}\text { Número de } \\
\text { animais }\end{array}$ & Fígado (g) & Baço (g) \\
\hline não & normo & 33 & 1,9580 & 0,2446 \\
sim & normo & 27 & 2,3968 & 0,3969 \\
nào & hipo & 30 & 1,0099 & 0,0690 \\
sim & hipo & 35 & 0,9697 & 0,0847 \\
\hline
\end{tabular}


MAGALHÃES, L.A. et al. Esquistossomose mansônica em camundongos experimentalmente subnutridos. Rev. Saúde públ., S.Paulo, $20: 362-8,1986$.

TABELA 6

Número médio ajustado de esquistossomos por sexo, granulomas hepáticos e ovos por grama de fezes na ocasião da necropsia dos camundongos.

\begin{tabular}{llcccccc}
\hline Infeç̧ão & Dieta & $\begin{array}{c}\text { Número de } \\
\text { animais }\end{array}$ & $\begin{array}{c}\text { Esquistossomos } \\
\text { machos }\end{array}$ & $\begin{array}{c}\text { Esquistossomos } \\
\text { fêmeos }\end{array}$ & $\begin{array}{c}\text { Total de } \\
\text { esquistossomos }\end{array}$ & $\begin{array}{c}\text { Granulomas } \\
\text { hepáticos }\end{array}$ & $\begin{array}{c}\text { No de ovos } \\
\text { g/fezes }\end{array}$ \\
\hline sim & normo & 22 & 21,9 & 16,1 & 38,0 & 4.106 & 3.455 \\
sim & hipo & 21 & 10,9 & 16,7 & 27,6 & 670 & 2.151 \\
\hline
\end{tabular}

TABELA 7

Comprimento médio ajustado, número de lóbulos testiculares e de ovos no útero dos esquistossomos recolhidos nos animais infectados por ocasiâo da necropsia.

\begin{tabular}{llcccccc}
\hline Infeç̧ão & Dieta & $\begin{array}{c}\text { Número de } \\
\text { machos }\end{array}$ & $\begin{array}{c}\text { Comprimento } \\
\text { de machos }\end{array}$ & $\begin{array}{c}\text { No de lóbulos } \\
\text { testiculares }\end{array}$ & $\begin{array}{c}\text { Número de } \\
\text { fêmeas }\end{array}$ & $\begin{array}{c}\text { Comprimento } \\
\text { de fêmeas }\end{array}$ & $\begin{array}{c}\text { No de ovos } \\
\text { no útero }\end{array}$ \\
\hline $\operatorname{sim}$ & normo & 134 & 6,5 & 7,5 & 78 & 7,7 & 1 \\
$\operatorname{sim}$ & hipo & 146 & 5,0 & 8,7 & 32 & 6,8 & 1 \\
\hline
\end{tabular}

(Comprimento em milímetros)

Houve significativamente menor número de esquistossomos machos nos animais subnutridos. A alimentação não interferiu no número de esquistossomos fềmeos.

O número de granulomas hepáticos foi muito menor nos animais submetidos a dieta hipoprotéica. Os animais subnutridos eliminaram número significativamente menor de ovos por grama de fezes.
TABELA 8

Mortalidade dos camundongos utilizados no experimento

\begin{tabular}{llcc}
\hline Infecção & Dieta & $\begin{array}{c}\text { Número de } \\
\text { animais }\end{array}$ & $\begin{array}{c}\text { Mortalidade } \\
\text { percentual }\end{array}$ \\
\hline não & normo & 42 & 0 \\
sim & normo & 33 & 18,18 \\
não & hipo & 26 & 3,80 \\
sim & hipo & 81 & 34,60 \\
\hline
\end{tabular}

TABELA 9

Números médios ajustados do leucograma dos camundongos utilizados no experimento por ocasiāo da necropsia.

\begin{tabular}{llcccrr}
\hline Infecção & Dieta & $\begin{array}{c}\text { Número de } \\
\text { animais }\end{array}$ & $\begin{array}{c}\text { Leucócitos } \\
\text { totais }\end{array}$ & Neutrófilos & Linfócitos & Eosinófilos \\
\hline não & normo & 21 & 13.200 & 2.096 & 10.708 & 396 \\
sim & normo & 22 & 12.442 & 3.363 & 7.918 & 1.161 \\
não & hipo & 23 & 6.600 & 1.229 & 4.695 & 676 \\
sim & hipo & 21 & 5.632 & 1.726 & 3.588 & 318 \\
\hline
\end{tabular}

Os esquistossomos recolhidos dos camundongos submetidos à dieta hipoprotéica foram significativamente menores em comprimento do que os recolhidos nos animais tratados com dieta normoprotéica. Não houve diferença significativa do número de lóbulos testiculares nem do número de ovos encuntrados no útero (em média, 1 por fêmea) dos esquistossomos recolhidos nos dois grupos de roedores (II e IV).
A taxa de mortalidade foi sensivelmente mais elevada nos animais infectados, notadamente nos submetidos à die ta hipoprotéica.

Os animais subnutridos apresentaram significativa leucopenia para a qual contribuiram todos os tipos de células brancas, acentuadamente os linfócitos. A leucopenia foi mais intensa nos animais subnutridos infectados. Ao contrário da acentuada eosinofi- 
MAGALHĀES, L.A. et al. Esquistossomose mansônica em camundongos experimentalmente subnutridos. Rev. Saúde públ., S.Paulo, $20 ; 362-8,1986$.

lia apresentada pelos camundongos infectados submetidos à dieta normoprotéica, os animais infectados subnutridos apresentaram eosinopenia quando comparados com seus congêneres não in. fectados.

\section{Estudo anátomo-patológico das vísceras}

Grupo I. Não infectados, submetidos à dieta normoprotéica.

Não verificamos alterações dignas de nota.

\section{Grupo II. Infectados, submetidos à dieta normo- protéica}

Foram observadas as seguintes alterações:

Figado. Numerosos granulomas em diversos estágios de evolução. Alguns granulomas exibiam necrose eosinofílica em cujas áreas adjacentes verificava-se fibrose com total desaparecimento da configuração hepatocitária. Ectasia dos capilares sinusoides, focos inflamatórios predominantemente neutrofilicos localizados principalmente junto aos espaços portais, não sendo, contudo, raros os localizados nas áreas intralobulares. Esses infiltrados eram difusos ou focais: Hiperplasia do SRE. Alterações regressivas hepatocitárias. Hipercromatismo de numerosos he. patócitos com marcante irregularidade do contorno da carioteca.

Baço. Presença de granulomas esquistossomóticos em diversos estágios evolutivos. Hiperplasia acentuada da polpa branca com evidente congestão da polpa vermelha, havendo, por vezes, áreas de hiperplasia de células reticulares.

Pulmões. Extensas áreas de atelectasia subpleu. rais não tendo sido rara a presença de congestão septal. Discreta hemorragia intra-alveolar.

\section{Grupo III. Não infectados, submetidos à dieta hipoprotéica}

Foram observadas as seguintes alterações:

Figado. Em algumas áreas verificaram-se alterações regressivas de grupos de hepatócitos. Em algumas regiões houve desaparecimento dos limites celulares. Grande número de hepatócitos bi-nucleados. $\mathrm{Em}$ alguns cortes verificou-se hiperplasia do SRE.

Baço. Discreta hiperplasia da polpa branca.

Pulmões. Sem alteração.

\section{Grupo IV. Infectados, submetidos à dieta hipo- protéica}

Foram observadas as seguintes alterações:

Figado. Presença de poucos granulomas. Os granulomas presentes eram visivelmente menores que os observados nos animais normoprotéicos. Alterações regressivas hepatocitárias, principalmente nas áreas correspondentes à presença de infiltrado inflamatório predominantemente neutrofílico. Discreta hiperplasia do SRE. Não observamos necrose eosinofílica. No mais, foram observados aspectos semelhantes aos do grupo III.

Baço. Ausência dos granulomas esquistossomóticos. Hiperplasia da polpa branca. Foi observado grande número de megacariócitos.

Pulmões. Sem alteração.

\section{DISCUSSÃO E CONCLUSÕES}

O menor tamanho apresentado pelos esquistossomos colhidos nos animais submetidos à dieta hipoprotéica sugere que os parasitos também sofreram os efeitos da subnutrição, principalmente os vermes machos que também apresentaram sua população aproximadamente reduzida pela metade.

De Witt8 (1975), em animais submetidos à dieta hipoprotéica, havia encontrado esquistossomos atrofiados. Em nosso experimento, os esquistossomos machos, recolhidos dos camundongos subnutridos, apesar de menores, apresentavam desenvolvimento sexual normal, pois não houve diferença significativa do número de lóbulos testiculares entre os vermes dos grupos II e IV. Também a ação ovipositora das fêmeas parece não ter sido alterada, pois constatamos o encontro de, em média, um ovo no útero de cada fêmea dos grupos II e IV. É curioso ressaltar que os esquistossomos fêmeos parecem ter sofrido menos os efeitos da subnutrição.

Como o número de ovos por grama de fezes foi significativamente menor nos animais subnutridos, acreditamos que este fato seja decorrente do menor número de vermes machos encontrados nesses roedores.

As reações de defesa do hospedeiro foram provavelmente afetados pela dieta. A reação granulomatosa foi muito menos intensa em número e em área de granuloma nos animais submetidos à dieta hipoprotéica.

$\mathrm{O}$ menor número de granulomas hepáticos e a menor área do granuloma poderá ser devido a menor capacidade reacional do hospedeiro subnutrido ou a modificações na estrutura dos ovos dos esquistossomos habitantes de roedores subnutridos (Akpom1. 1981).

Apesar do reduzido número de lesões granulomatosas observadas nos animais subnutridos, este grupo de roedores acusou elevada taxa de mortalidade $(34,6 \%)$ quando comparada com a do grupo de animais tratados com dieta normoprotéica $(18,18 \%)$.

Houve acentuada leucopenia nos animais submetidos à dieta hipoprotéica, principalmente devido a linfopenia observada. Estes fatos acentuaram-se nos animais submetidos à infecção e à dieta hipoprotéica. 
A eosinopenia que ocorreu nos animais infectados subnutridos parece demonstrar que a dieta hipoprotéica interferiu no sistema imunitário do hospedeiro.

Entre os 30 e 90 dias (Tabela 4) a evolução do peso corporal nos grupos normoprotéicos foi maior quando comparada com os grupos hipoprotéicos, porém menor no grupo submetido a infecção por $S$. mansoni. O grupo infectado apresentou um acréscimo de $48 \%$ em seu peso corporal contra $72 \%$ apresentado pelo grupo não infectado.
Nos grupos de animais submetidos à dieta hipoprotéica as médias de peso corporal mantiveram-se sempre abaixo daquelas verificadas nos grupos normoprotéicos. A partir da data de infecção observouse aumento de peso corporal, porém bem inferior ao observado no grupo normoprotéico. $O$ grupo hipoprotéico infectado teve um aumento de $35 \% \mathrm{em}$ seu peso corporal e o grupo não infectado, $36 \%$.

Concluimos que os camundongos submetidos à dieta hipoprotéica resistiram menos à infecção esquistossomótica apesar de terem apresentado menor quantidade de lesões granulomatosas.

MAGALHÃES, L.A. et al. [ Mansoni schistosomiasis in experimentally undemourished mice ] Rev. Saúde públ., S.Paulo, $20: 362-8,1986$.

ABSTRACT: Mansoni schistosomiasis was studied in mice fed on a low protein diet. Four groups of the Swiss breed Mus musculus were used in an experiment with two factors, each with two levels: 1 -non-infected, normal diet; 2 - infected, normal diet; 3 - non-infected, low protein diet; 4 - infected, low protein diet. The mice were killed for observation at age 90 days, after 60 days of infection, for those infected. It was found that the worms suffered the effects of malnutrition, mainly males, whose population count was cut by half, in addition to poor individual growth. The hepatic granuloma count was found to be smaller in the undernourished group; while the corresponding lesions were also generally smaller. There was a marked leukopenia in the malnourished mice, even more so in the infected mice. The severe lymphopenia and eosinopenia observed suggest that the immunologic system of the host was affected by malnutrition. Mortality rates were far larger in the infected, low protein diet group. One may then surmise that the malnourished mice offered lower resistance to the infection, their lower number of granuloma notwithstanding.

UNITERMS: Schistosomiasis mansoni, complications. Protein deficiency. Mice, parasitology. Mice, experimental infection. Schistosoma mansoni.

\section{REFERENCIAS BIBLIOGRAFICAS}

1. AKPOM, C.A. Supression of granuloma formation around Schistosoma mansoni eggs in severe protein malnutrition: the role of the egg. Trans.roy Soc.trop. Med.Hyg., 75 : 444-6, 1981.

2. AKPOM, C.A. \& WARREN, K.S. Calorie and protein malnutrition in chronic murine schistosomiasis mansoni, effect on the parasite and the host.J. infect.Dis., 123: $6-14,1975$.

3. AKPOM, C.A. \& WARREN, K.S. The inhibition of granuloma formation around Schistosoma mansoni eggs. VI - Protein calorie and vitamin deficiency. Amer.J.Pathol., 79: 435-52, 1975.

4. BRENER, Z,; PELLEGRINO, J. \& OLIVEIRA, F.D. Terapêutica experimental da esquistossomose mansoni: aplicação do método de isolamento de granulomas do fígado de camundongos. Rev.bras.Malar., 8: $583 \cdot 7,1956$.

5. COUTINHO, E. Patobiologia da desnutrição nas doenças parasitárias. Mem.Inst. Oswaldo Cruz, 75(3/4): $63 \cdot 76,1980$.

6. COUTINHO, E.; BARBOSA, F.S.; BARBOSA, J.M.; PESSOA, P.; PINTO, R.F.; OLIVEIRA, P.A. \& RODRIGUES, B.A. Inquérito clínico-nutricional e antropométrico preliminar, em áreas endêmicas de esquistossomose mansônica, no Nordeste do Brasil. Rev.Soc.bras.Med.trop., 6:211-36, 1972.
7. COU'TINHO-ABATH, E.; MAGALHÄES FILHO, A. \& BARBOSA, J.M. Lesōes hepáticas no camundongo albino experimentalmente infestado por Schistosoma mansoni e submetido a dietas de diferente teor protéico. Rev.Inst.Med.trop.S.Paulo, 4 : $311-22,1962$.

8. DE WITT, W.B. Experimental schistosomiasis mansoni in mice maintained on nutritionally deficient diets. I. Effects of a torula yeast ration deficient in factor ${ }^{3}$, vitamin E, and cystine. J.Parasit., 43: 119-28, 1975.

9. DE WITT, W.B. Experimental schistosomiasis mansoni in mice maintained on nutritonally deficient diets. II. Survival and development of Schistosoma man. soni in mice maintained on a torula yeast diet deficient in factor ${ }^{3}$, vitamin $\mathrm{E}$, and cystine. J.Parasit., $43: 129-35,1975$.

10. KNAUFT, R.F. \& WARREN, K.S. The effect of calorie and protein malnutrition on both the parasite and the host in acute murine schistosomiasis mansoni. J.infect.Dis., 120:560-75, 1969.

11. KOMIYA, Y. \& KOBAYASHI, A. Evaluation of Kato's thick smear technic with a cellophane cover for helminth eggs in feces. Jap.med.Sci.Biol., $19: 59-64$, 1966. 
MAGALHĀES, L.A. et al. Esquistossomose mansônica em camundongos experimentalmente subnutridos. Rev. Saúde públ., S.Paulo, $20: 362-8,1986$.

12. MADI, K. \& CAMPOS, S.D. Desnutrição experimental e resultados anatomopatológicos e bioquímicos da administração de dietas hipoprotéicas a ratos albinos jovens. Mem.Inst.Oswaldo Cruz, 73: 153-81, 1975 .

13. MAGALHÃES, L.A. Técnica para avaliação da viabilidade de penetração de cercárias de Schistosoma mansoni em Mus musculus. Hospital, Rio de Janeiro, 75: 137-40, 1969.
14. SNEDECOR, G.W. \& COCHRAN, W.G. Statistical methods. $7^{\text {th }}$ ed. Ames, lowa State University Press. 1980.

15. YOLLES, T.K.; MOORE, D.U.; DE GINSTI, D.L.; RIPSON, C.A. \& MELENEY, H.E. A technique for the perfusion of laboratory animals for the recovery of schistosomes. J.Parasit., 33:419-26, 1947.

Recebido para publicaçāo em 03/03/1986 Aprovado para publicaçāo em 09/06/1986 